\title{
Effect of friction at chip-tool interface on chip geometry and chip snarling in tapping process
}

Yasuyoshi Saito ${ }^{1 *}$, Shoki Takiguchi ${ }^{1}$, Takeshi Yamaguchi ${ }^{1}$, Kei Shibata $^{1}$,

Takeshi Kubo $^{2}$, Wataru Watanabe ${ }^{2}$, Satoru Oyama ${ }^{2}$, Kazuo Hokkirigawa ${ }^{1}$

${ }^{1}$ Graduate School of Engineering, Tohoku University, 6-6-01 Aramaki Aza-Aoba, Aoba-ku, Sendai, Miyagi 980-8579, Japan, saito@gdl.mech.tohoku.ac.jp

${ }^{2}$ MIYAGITANOI MFG. CO., LTD, 15-1 Shichigashuku-machi Aza-Hagisaki, Katta-gun, Miyagi 989-0537, Japan

*Corresponding author

Tel: +81-22-795-6897/E-mail: saito@gdl.mech.tohoku.ac.jp 
Abstract

During tapping processes, the chip snarling problem must be resolved to improve manufacturing efficiency. In this study, we used an electroless plating method to develop a tapping tool coated with $\mathrm{Ni}-\mathrm{P} / \mathrm{abrasive-particle} \mathrm{composite} \mathrm{film} \mathrm{to} \mathrm{solve} \mathrm{the} \mathrm{chip} \mathrm{snarling} \mathrm{problem.} \mathrm{The}$ tapping test was conducted at $10 \mathrm{~m} / \mathrm{min}$ (conventional cutting velocity) and $50 \mathrm{~m} / \mathrm{min}$ with a machining center. The cutting torque and thrust force were measured using a dynamometer. The results of the tapping test indicate that the developed tapping tool coated with the composite film prevented chip snarling at $10 \mathrm{~m} / \mathrm{min}$ and $50 \mathrm{~m} / \mathrm{min}$. The dimensionless diameter for the developed tapping tool, which is the diameter of the chip curl divided by the width of the helical flute, was less than 1.0 for both cutting conditions, whereas that for steam-treatment and TiCN film is greater than 1.0. Furthermore, we estimated the coefficient of friction between the rake face of the cutting edge of the tapping tool and the chip from the thrust force and cutting torque. The estimated coefficient of friction for the tapping tool coated with the composite film $(>1.23)$ was greater than that for the other methods $(<1.23)$. These results indicate that a high coefficient of friction $(>1.23)$ is necessary to prevent chip snarling, and due to the high coefficient of friction, the developed tapping tool can prevent chip snarling even at a speed of $50 \mathrm{~m} / \mathrm{min}$.

Keywords: Chip snarling; Chip geometry; Cutting resistance; Electroless plating; Tapping tool 


\section{Introduction}

The tapping process is one of the most important cutting processes when machining a thread hole. Increased processing efficiency and tool service life have long been desired for this tapping process. The problem of chip snarling of cut taps is one problem preventing improved manufacturing efficiency and tool service life, because snarled chips on the tapping tool must be manually removed and at times break products and tools [1-4].

In efforts to address this problem, a hard or lubricant coating has been applied to tapping tools and its cutting performance has been evaluated. Jin et al. developed the cubic boron nitride (cBN)-coated tap and clarified that $\mathrm{cBN}$-coated taps proved to be effective in cutting beta-titanium alloys with improvements in accuracy, tapping resistance, and tool life over commercially available conventional coated taps [5]. Reiter et al. and Derflinger et al. showed that a tapping tool with a hard lubricant coating yields excellent friction behavior, and excellent abrasive and adhesive wear resistance [6, 7]. However, chip snarling still occurred with the use of this hard coating. Yan et al. also reported that smooth and hard coatings cause chip snarling [8]. In order to solve the problem, the chip geometry is controlled by the tool geometry and cutting condition during turning $[9,10]$ and drilling $[11,12]$, but there are found no literature indicating effective methods to prevent chip snarling during tapping.

Saito et al. developed a tapping tool coated with nickel-phosphorus ( $\mathrm{Ni}-\mathrm{P}) /$ abrasive-particle composite film and succeeded in preventing chip snarling with a tapping tool at five times the cutting velocity (50 $\mathrm{m} / \mathrm{min}$ ) compared with the conventional cutting velocity $(10 \mathrm{~m} / \mathrm{min})[13,14]$. Saito et al. also found that the chip curl diameter of an evacuated chip with no associated chip snarling was shorter than the width of the flute of the tap, while that with chip snarling was wider than the width of the flute. Thus, to generate chips with a shorter curl diameter could be a key factor in preventing chip snarling. In the cutting process, the coefficient of friction between the rake face of the cutting tool and the chip affects the chip curl diameter [15]. However, the coefficient of friction between the rake face of each cutting edge of the tapping tool is difficult to measure. Thus, the relationship between the coefficient of friction at the rake face-chip interface and chip snarling occurrence is unclear.

The purposes of this study were to estimate the coefficient of friction at the rake face of each cutting edge of the tapping tool from the cutting torque and thrust force measured during tapping, and to investigate the relationship between the chip curl diameter and the estimated coefficient of friction. Then the mechanism that prevents chip snarling with the tapping tool coated with the composite film was discussed.

\section{Experimental methods}

\subsection{Tapping tool coated with Ni-P/abrasive particle composite film}

Figure 1 shows SEM images of the tapping tool coated with $\mathrm{Ni}-\mathrm{P} / \mathrm{abrasive-particle} \mathrm{composite} \mathrm{film.}$ Cubic boron nitride $(\mathrm{cBN})$ particles or silicon carbide $(\mathrm{SiC})$ particles were used as the abrasive particles of the composite film. The diameters of the $\mathrm{cBN}$ and $\mathrm{SiC}$ particles were $10 \mu \mathrm{m}$ and $1 \mu \mathrm{m}$, respectively. We used a high-speed steel (HSS) spiral-tap and it was coated with the composite film using the electroless plating method. The composite film was heat-treated at $573 \mathrm{~K}$ to increase the hardness of the Ni-P matrix [16]: the 
hardness of Ni-P plating increased from $6.6 \mathrm{GPa}$ without hardening to $11.6 \mathrm{GPa}$ with hardening. The arithmetic mean surface roughness of the $\mathrm{Ni}-\mathrm{P} / \mathrm{cBN}$ (Fig. 2(a)) film and the Ni-P/SiC (Fig. 2(b)) film were 1.2 and $0.4 \mu \mathrm{m}$, respectively.

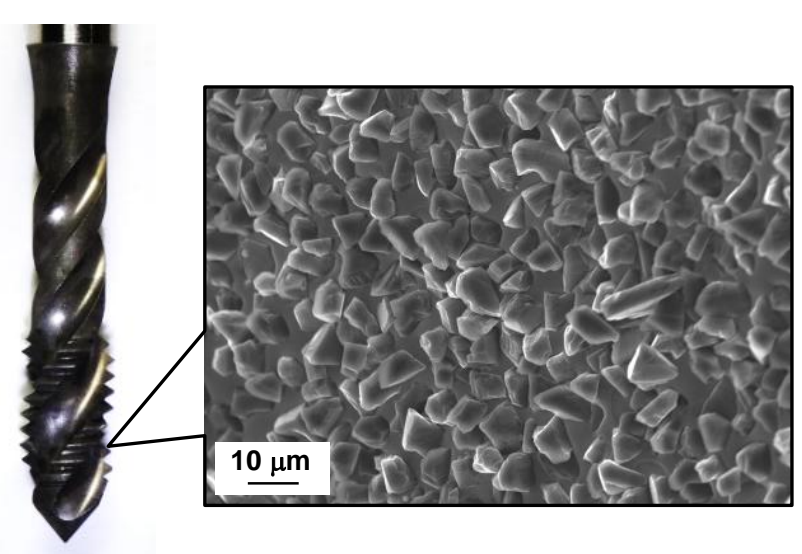

(a) $\mathrm{Ni}-\mathrm{P} / \mathrm{cBN}$ film

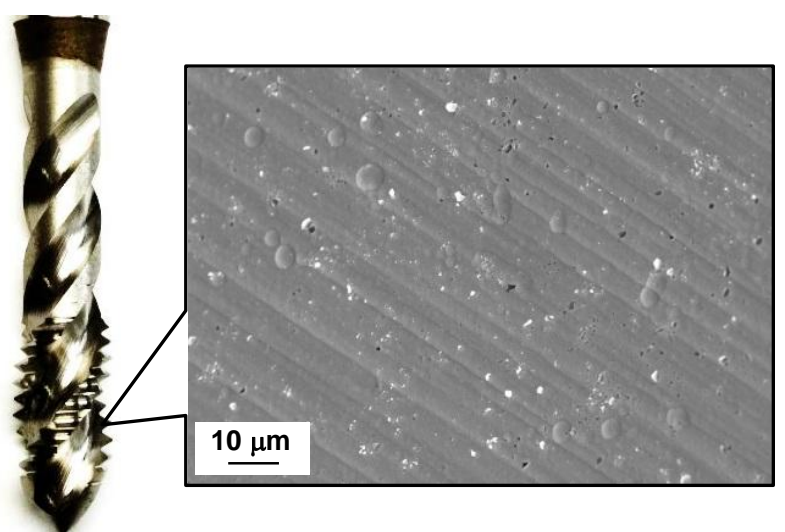

(b) $\mathrm{Ni}-\mathrm{P} / \mathrm{SiC}$ film

Figure 1 SEM images of the tapping tool coated with $\mathrm{Ni}-\mathrm{P} /$ abrasive-particle composite film

\subsection{Tapping test}

Tapping tests were conducted with the machining center shown in Fig. 2. Table 2 shows the experimental conditions for the tapping tests. The test tapping tool was a spiral-tap tool (HSS, M6 $\times 1$ ), which had eight cutting edges and three helical flutes. The shape parameter of spiral-tap is shown in Table 1. The surface treatment was a steam treatment, which makes an oxide steel $\left(\mathrm{Fe}_{3} \mathrm{O}_{4}\right)$ layer, coated with titanium carbo-nitride $(\mathrm{TiCN})$ film, $\mathrm{Ni}-\mathrm{P} / \mathrm{cBN}$ film, or $\mathrm{Ni}-\mathrm{P} / \mathrm{SiC}$ film. Steam treatment is the conventional surface treatment for tapping tools [17]. The thickness of the $\mathrm{Ni}-\mathrm{P} / \mathrm{cBN}$ film was $20 \mu \mathrm{m}$, that of the Ni-P/SiC film

Table 1 Shape parameter of spiral-tap

\begin{tabular}{ll}
\hline Normal size & M6×1 \\
\hline Pitch $P, \mathrm{~mm}$ & 1 \\
\hline Number of helical flutes $N_{\mathrm{f}}$, flutes & 3 \\
\hline Number of cutting edges $N_{\mathrm{e}}$, edges & 8 \\
\hline Width of helical flute $W_{\mathrm{t}}, \mathrm{mm}$ & 3.2 \\
\hline Lead angle $\gamma$, deg & 3.03 \\
\hline Chamfer angle $\beta$, deg & 15.4 \\
\hline Torsion angle $\theta$, deg & 43.4 \\
\hline Rake angle $\alpha_{\mathrm{n}}$, deg & 5.5 \\
\hline
\end{tabular}


was $5 \mu \mathrm{m}$ and that of the other films was $1 \mu \mathrm{m}$. The diameter of the prepared holes for the tapping tool coated with $\mathrm{Ni}-\mathrm{P} / \mathrm{cBN}$ film was $5.15 \mathrm{~mm}$ and that of the others was $5.10 \mathrm{~mm}$. The workpiece material was carbon steel (JIS S45C) in the form of rectangular block of $14.0 \times 310.0 \times 450.0 \mathrm{~mm}^{3}$. The cutting velocities were $10 \mathrm{~m} / \mathrm{min}$ (conventional cutting velocity) and $50 \mathrm{~m} / \mathrm{min}$. Emulsion cutting oil was used during the tapping process. 25 through holes were processed for each cutting condition, and 30 cutting chips were collected after each tapping test.

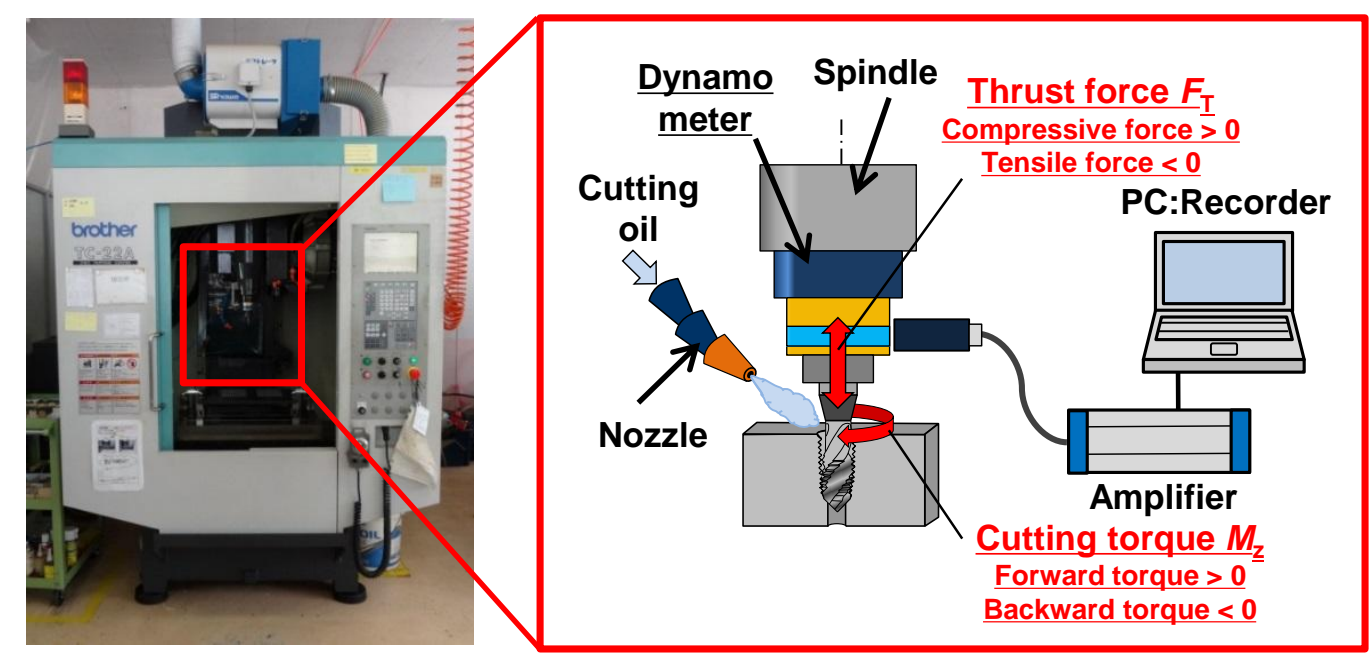

Figure 2 Vertical-type machining center

Table 2 Experimental conditions

\begin{tabular}{ll}
\hline & Surface treatment \\
\cline { 2 - 2 } Surface treatment & Steam-treatment \\
(HSS spiral-tap, M6 $\times 1)$ & TiCN film \\
& Ni-P/cBN film \\
& Ni-P/SiC film \\
\hline Workpiece material & Carbon steel (JIS:S45C) \\
\hline Cutting velocity $V_{\mathrm{r}}, \mathrm{m} / \mathrm{min}$ & 10,50 \\
\hline Number of cutting process $N$, holes & 25 \\
\hline Lubricant condition & Emulsion cutting oil \\
\hline
\end{tabular}




\subsection{Estimation of coefficient of friction from thrust force and cutting torque}

The coefficient of friction between the rake face of the tool and the chip was estimated from the thrust force and cutting torque. The thrust force and cutting torque during tapping process were measured using a dynamometer. Figure 3 shows a typical cutting torque curve. The points A, B, C, and D are the times at which the first cutting edge makes contact with the workpiece, when the eighth cutting edge begins to cut the workpiece, when the first cutting edge finishes cutting, and when the eighth cutting edge is extracted from the bottom of the hole, respectively. We used the thrust force and cutting torque at point B to estimate the mean cutting resistance of the eight cutting edges. Note that we assume that the cutting torque and thrust force obtained in the tapping test are caused only by the cutting resistance of the eight cutting edges and that the friction force at the workpiece-flank face of the tapping tool is ignored because the contact area is very small.

The coordinates between the cutting force components at the rake face $\left(F_{\mathrm{X}}, F_{\mathrm{Y}}, F_{\mathrm{Z}}\right)$ and the measured force components $\left(F_{\mathrm{M}}, F_{\mathrm{T}}, F_{\mathrm{Z}^{*}}\right)$ were transformed as follows, with the chamfer angle $\beta$, the torsion angle $\theta$ and the rake angle $\alpha_{\mathrm{n}}$ as shown in Fig. 4:

$$
\begin{aligned}
\left(\begin{array}{l}
F_{\mathrm{X}} \\
F_{\mathrm{Y}} \\
F_{\mathrm{Z}}
\end{array}\right) & =\left(\begin{array}{ccc}
1 & 0 & 0 \\
0 & \cos \beta & -\sin \beta \\
0 & \sin \beta & \cos \beta
\end{array}\right)\left(\begin{array}{ccc}
\cos \theta & -\sin \theta & 0 \\
\sin \theta & \cos \theta & 0 \\
0 & 0 & 1
\end{array}\right)\left(\begin{array}{ccc}
\sin \alpha_{\mathrm{n}} & 0 & \cos \alpha_{\mathrm{n}} \\
0 & 1 & 0 \\
-\cos \alpha_{\mathrm{n}} & 0 & \sin \alpha_{\mathrm{n}}
\end{array}\right)\left(\begin{array}{c}
F_{\mathrm{M}} \\
F_{\mathrm{T}} \\
F_{\mathrm{Z}^{*}}
\end{array}\right) \\
& =\left(\begin{array}{ccc}
\sin \alpha_{\mathrm{n}} \cos \theta & -\sin \alpha_{\mathrm{n}} \sin \theta \cos \beta+\cos \alpha_{\mathrm{n}} \sin \beta & \sin \alpha_{\mathrm{n}} \sin \theta \sin \beta+\cos \alpha_{\mathrm{n}} \cos \beta \\
\sin \theta & \cos \alpha_{\mathrm{n}} \cos \beta & -\cos \theta \sin \beta \\
-\cos \alpha_{\mathrm{n}} \cos \theta & \cos \alpha_{\mathrm{n}} \sin \beta+\sin \alpha_{\mathrm{n}} \sin \beta & -\cos \alpha_{\mathrm{n}} \sin \theta \sin \beta+\sin \alpha_{\mathrm{n}} \cos \beta
\end{array}\right)\left(\begin{array}{c}
F_{M} \\
F_{T} \\
F_{Z *}
\end{array}\right)
\end{aligned}
$$

where $F_{\mathrm{M}}$ is the circumferential force, which is the cutting torque divided by the radius of tapping tool; $F_{\mathrm{T}}$ is the axial force, which is the thrust force measured with the dynamometer; and $F_{\mathrm{Z}^{*}}$ is the radial force.

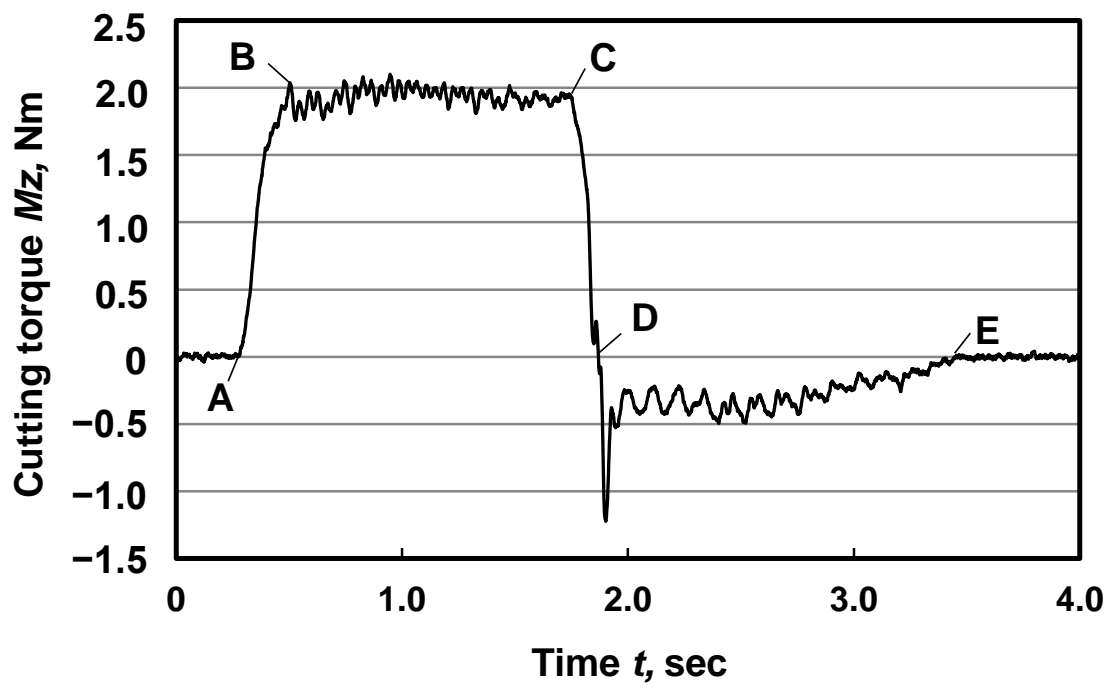

Figure 3 Sample cutting torque curve

(Tapping tool coated with TiCN film; cutting velocity; $10 \mathrm{~m} / \mathrm{min}$ ) 
Based on the assumption that the chip flow angle $\eta$ is equivalent to the direction of friction force [18],

$2 \quad F_{Z^{*}}$ can be calculated as follows:

$$
F_{Z^{*}}=\frac{\left(\sin \theta-\sin \alpha_{\mathrm{n}} \cos \theta \tan \eta\right) F_{\mathrm{M}}+\left(\cos \theta \sin \beta+\sin \alpha_{\mathrm{n}} \sin \theta \cos \beta \tan \eta-\cos \alpha_{\mathrm{n}} \sin \beta \tan \eta\right) F_{\mathrm{T}}}{\cos \theta \cos \beta \tan \eta+\sin \alpha_{\mathrm{n}} \sin \theta \sin \beta \tan \eta+\cos \theta \sin \beta}
$$

The chip flow angle $\eta$ is obtained for the geometric calculating because the chip flows along the face of thread. The coefficient of friction was calculated using the following formula:

$$
\mu=\frac{\sqrt{F_{X}^{2}+F_{Y}^{2}}}{F_{Z}} \quad \begin{gathered}
5 \\
(3) \\
7
\end{gathered}
$$

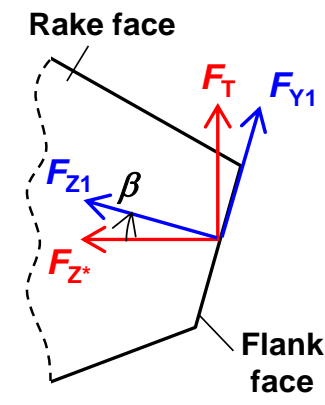

(a) With chamfer angle $\beta$

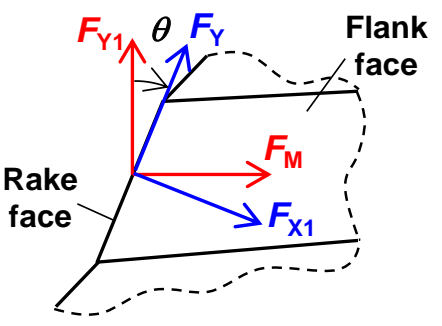

(b) With torsion angle $\theta$

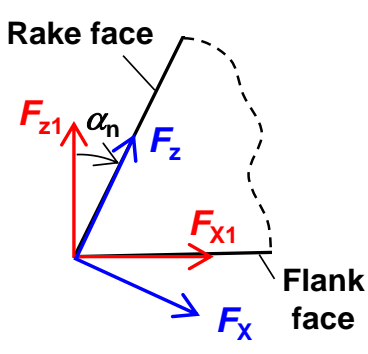

(c) With rake angle $\alpha_{n}$

Figure 4 Schematics of transformation of the coordinates between cutting force components at the rake face and the measured force components

\section{Results and discussion}

\subsection{Chip snarling and chip curl diameter}

Figures 5 and 6 show snapshots of the tapping tools after cutting 25 thread holes at 10 and $50 \mathrm{~m} / \mathrm{min}$, respectively. The tapping tool that had undergone steam-treatment had no chip snarling at $10 \mathrm{~m} / \mathrm{min}$ (Fig. 5(a)) but experienced chip snarling at $50 \mathrm{~m} / \mathrm{min}$ (Fig. 6(a)). The tapping tool coated with TiCN film experienced chip snarling at both cutting velocities (Figs. 5(b) and 6(b)). In contrast, the tapping tools coated with $\mathrm{Ni}-\mathrm{P} /$ abrasive-particle composite films prevented chip snarling at both cutting velocities, as shown in Figs. 5(c), 5(d), 6(c), and 6(d).

30 chips after the tapping test for each tapping tool were collected. The geometry of collected chips during tapping test without chip snarling, particularly the chip curl diameter, was different from that with chip snarling. Thus, we calculated and compared the dimensionless diameters of chip curl $D_{\mathrm{d}}$, which is the diameter of the chip curl $D_{\mathrm{c}}$ (Fig, 7 (a)) divided by the width of the helical flute $W_{\mathrm{t}}$ (Fig. 7(b)). A $D_{\mathrm{d}}$ value less than 1.0 indicates that the diameter of the chip curl is shorter than the width of the flute. Figure 8 shows the maximum values of $D_{\mathrm{d}}\left(D_{\mathrm{d}, \max }\right)$ among the 30 chips collected for each tapping tool at each cutting velocity condition. For the tapping tool with stream-treatment, the value of $D_{\mathrm{d} \text {, max }}$ increased with an increase of cutting velocity and exceeded 1.0 at $50 \mathrm{~m} / \mathrm{min}$. For the tapping tool coated with TiCN film, the values of $D_{\mathrm{d}, \max }$ were higher than those for other tapping tools and more than 1.0. On the other hand, the values of $D_{\mathrm{d}}$, $\max$ was less than 1.0 at both $10 \mathrm{~m} / \mathrm{min}$ and $50 \mathrm{~m} / \mathrm{min}$. It is clearly demonstrated in this figure that the value of $D_{\text {d, max }}$ was larger than 1.0, i.e., the diameter of the chip curl was longer than the width of helical flute, when 
the chips were snarled on the tapping tool. In this case, the enlarged chips contacted with the wall of the helical flute and the force applied to the chips from the wall possibly prevented evacuation of the chips. In 3 addition, if a chip remains on the tapping tool, successive chip evacuation is limited by the remained chip and the chip snarling is promoted. In contrast, the value of $D_{\mathrm{d} \text {, max }}$ was less than 1.0 for the developed tapping tools even at $50 \mathrm{~m} / \mathrm{min}$. Thus, the chips could evacuate without restraint from the helical flute. Therefore, these results confirm that a decrease in the chip curl diameter is effective in preventing chip snarling.

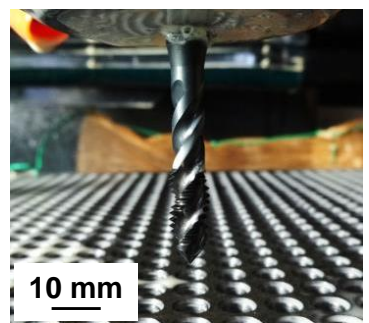

(a) Steam-treatment

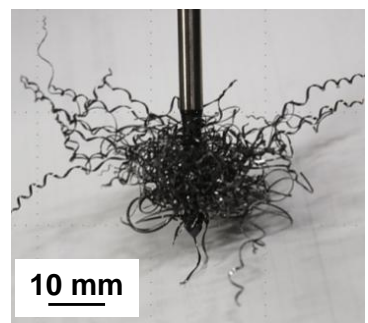

(b) TiCN film

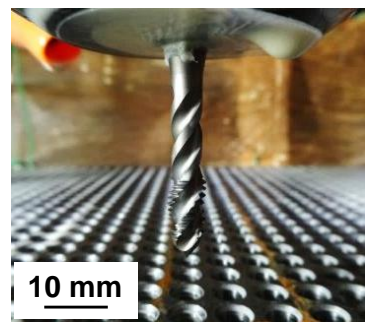

(c) $\mathrm{Ni}-\mathrm{P} / \mathrm{cBN}$ film

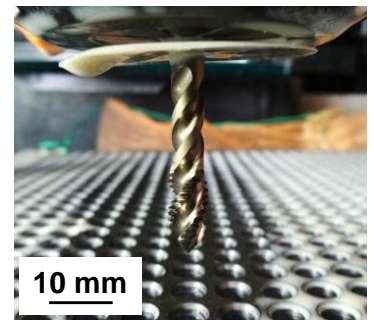

(d) $\mathrm{Ni}-\mathrm{P} / \mathrm{SiC}$ film

Figure 5 Snapshots of the tapping tool after cutting 25 thread holes at a $10 \mathrm{~m} / \mathrm{min}$ cutting tool

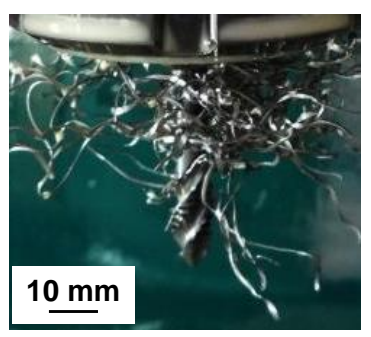

(a) Steam-treatment

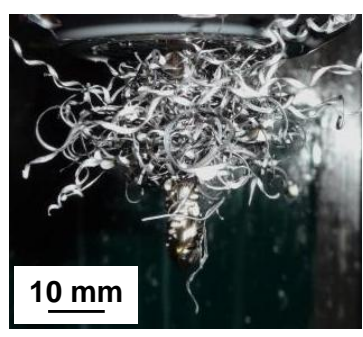

(b) TiCN film

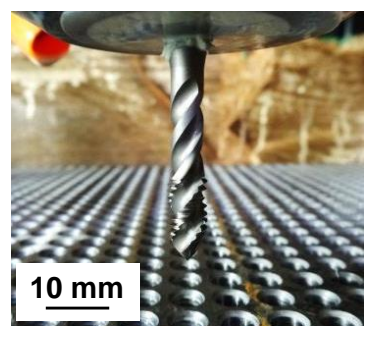

(c) $\mathrm{Ni}-\mathrm{P} / \mathrm{cBN}$ film

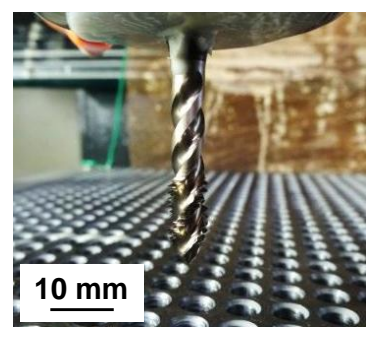

(d) $\mathrm{Ni}-\mathrm{P} / \mathrm{SiC}$ film

Figure 6 Snapshots of the tapping tool after cutting 25 thread holes at a $50 \mathrm{~m} / \mathrm{min}$ cutting tool

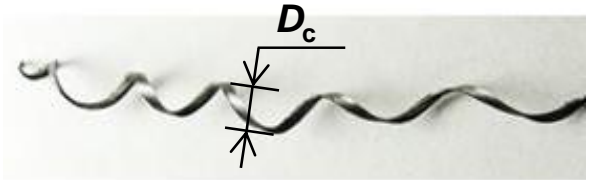

$5 \mathrm{~mm}$

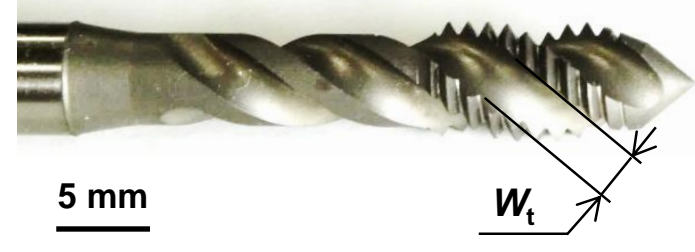

(b) Width of spiral flute

(a) Diameter of chip curl

Figure 7 Geometric parameters of chip and tapping tool 


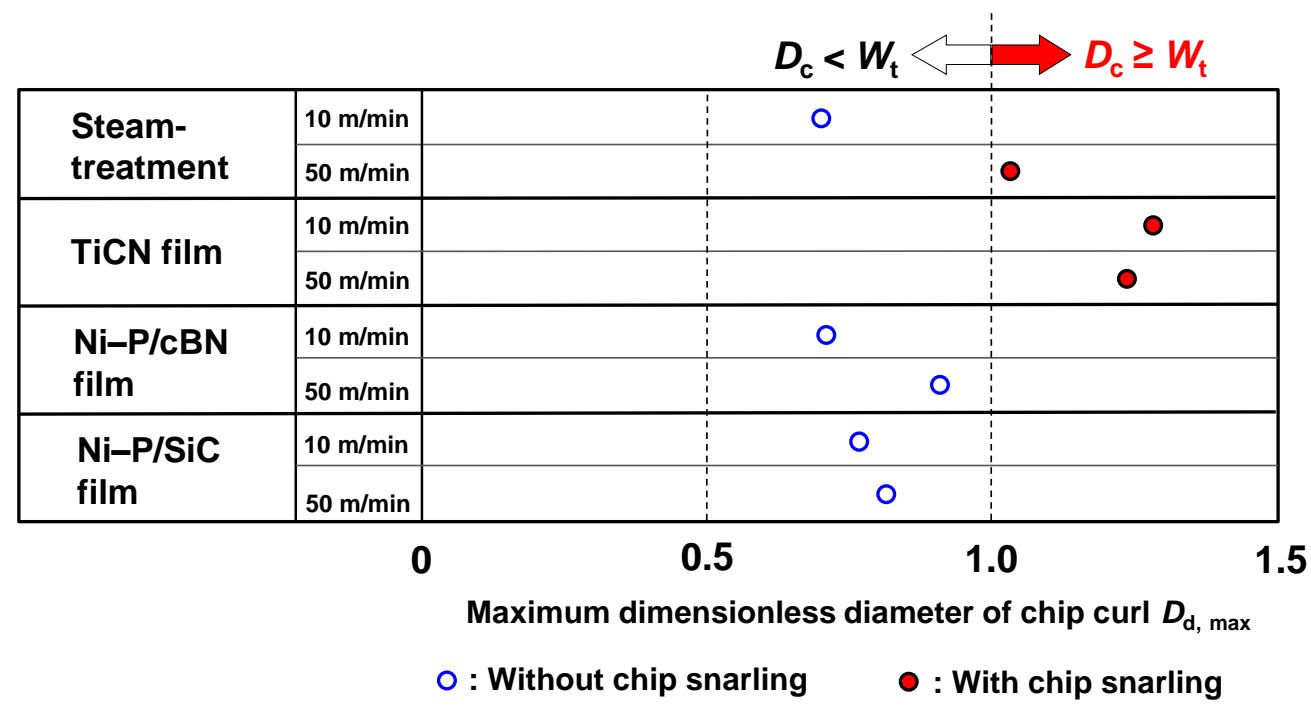

Figure 8 Maximum dimensionless diameters of chip curls

\subsection{Relationship between the estimated coefficient of friction and chip curl diameter}

Figures 9 and 10 show the changes in the cutting torque and the thrust force, respectively, at 10 and 50 $\mathrm{m} / \mathrm{min}$ with respect to the number of cutting processes. As shown in the figures, the cutting torques of the developed tapping tools with composite films tend to be higher those of the others whereas the magnitudes of the thrust forces for the developed tapping tools with composite film tend to be lower. The cutting torques for the tapping tool with steam treatment and that coated with TiCN film tend to decrease with an increase of cutting velocity and the thrust forces for the tapping tools increased with an increase of cutting velocity; however, the change in the cutting torques and thrust forces for the tapping tools coated with composite films were smaller. The differences in thrust force at $50 \mathrm{~m} / \mathrm{min}$ between the tapping tools coated with the composite films and the other tapping tools (steam-treatment and TiCN coating) were more significant than those at $10 \mathrm{~m} / \mathrm{min}$. Such low thrust force for developed tapping tool prevents the tapping tool from being drawn into the workpiece along the thread pitch, as compared with the other tapping tool results.

Figure 11 shows the mean coefficients of friction estimated from the cutting torque and thrust force for the number of cutting process from 6 holes to 10 holes using Eqs. (1), (2), and (3). The mean coefficient of friction at $50 \mathrm{~m} / \mathrm{min}$ is lower than that at $10 \mathrm{~m} / \mathrm{min}$. The reason for this is that the hardness of the workpiece is softened because of its increased temperature at $50 \mathrm{~m} / \mathrm{min}$ compared with that at $10 \mathrm{~m} / \mathrm{min}$. The coefficients of friction for the developed tapping tools were greater than those for the steam-treatment and TiCN film at both cutting speeds, which could have resulted from the ploughing friction of the abrasive particle on the tapping tool. Furthermore, the coefficient of friction was less than 1.23 when the chips were snarled on the tapping tool. 


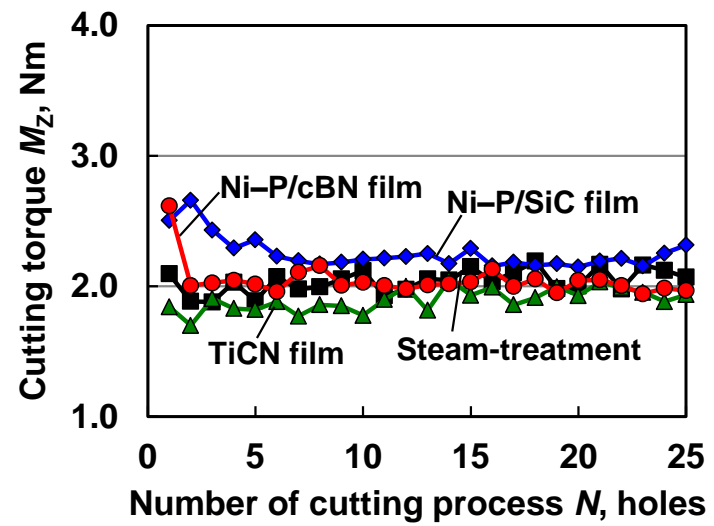

(a) Cutting torque

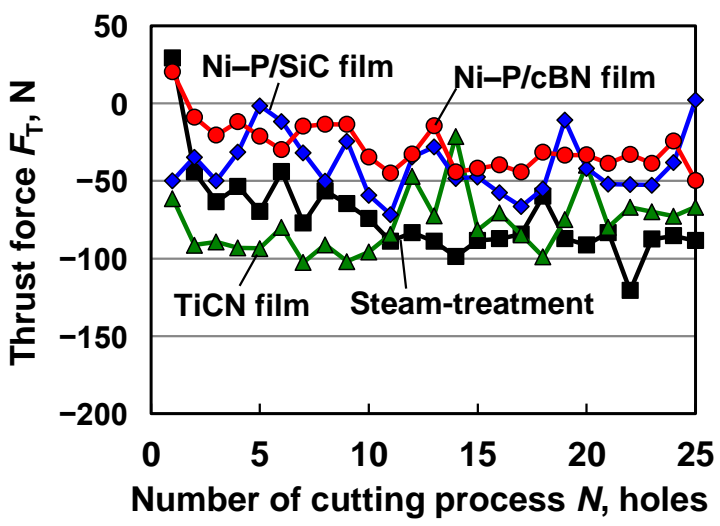

(b) Thrust force

Figure 9 Cutting resistance with respect to the number of cutting processes at $10 \mathrm{~m} / \mathrm{min}$ cutting velocity

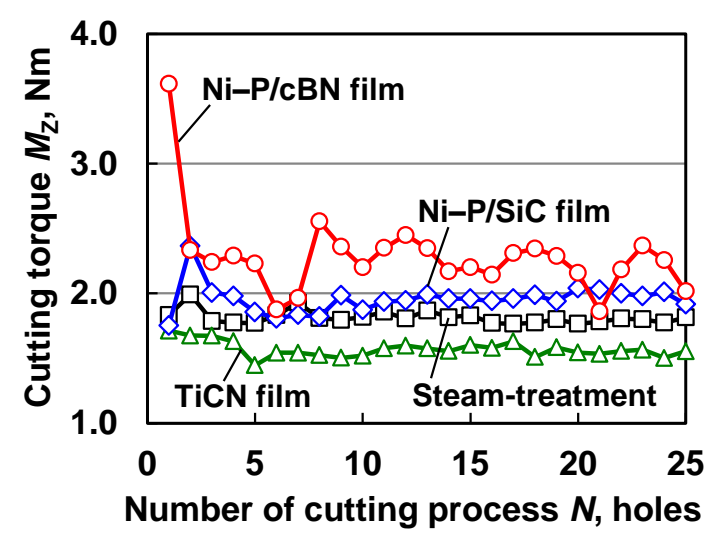

(a) Cutting torque

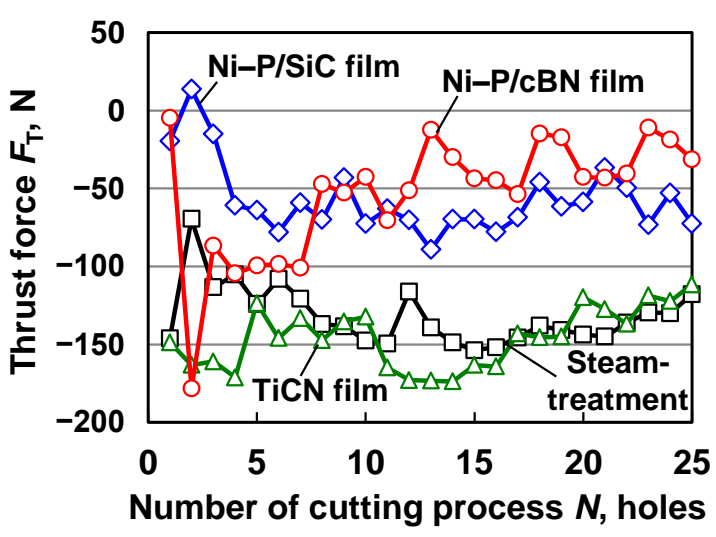

(b) Thrust force

Figure 10 Cutting resistance with respect to the number of cutting processes at $50 \mathrm{~m} / \mathrm{min}$ cutting velocity

The relationship between the value of $D_{\mathrm{d} \text {, max }}$ and the mean coefficient of friction at chip-tool rake face is shown in Fig. 12. The value of $D_{\mathrm{d}, \max }$ tends to decrease with an increased mean coefficient of friction. Furthermore, the maximum diameter of the chip curl was less than 1.0 when the friction coefficient was bigger than 1.23. Thus, these results clearly demonstrate that the increase in coefficient of friction at chip-tool rake face is effective in decreasing the chip curl diameter, which results in preventing chip snarling.

There are two hypotheses of decreasing the diameter of chip curl by the high friction. One is the friction heat theory. The diameter of the chip curl is considered to decrease because the chip surface expands due to the frictional heat [18]. The increased coefficient of friction could increase the frictional heat. The other is the secondary flow theory [15]. The secondary flow is the phenomenon that the plastic flow velocity in the part of the chip adjacent to the tool surface is reduced by the friction at chip-tool rake face. The effect of secondary flow increases with an increase of the friction. Thus, the developed tapping tool with the composite film reduced the diameter of the chip curls due to the high coefficient of friction at the rake face, 
1 resulting in the prevention of chip snarling. In future, it is necessary to test if the tapping tool coated with 2 composite film is applicable to workpiece materials such as low-carbon steel, austenitic stainless steel, etc. to 3 show the practical efficacy.

\begin{tabular}{|c|c|c|}
\hline & $10 \mathrm{~m} / \mathrm{min}$ & $50 \mathrm{~m} / \mathrm{min}$ \\
\hline With chip snarling & $\square$ & $\mathbb{W}$ \\
\hline Without chip snarling & & \\
\hline
\end{tabular}

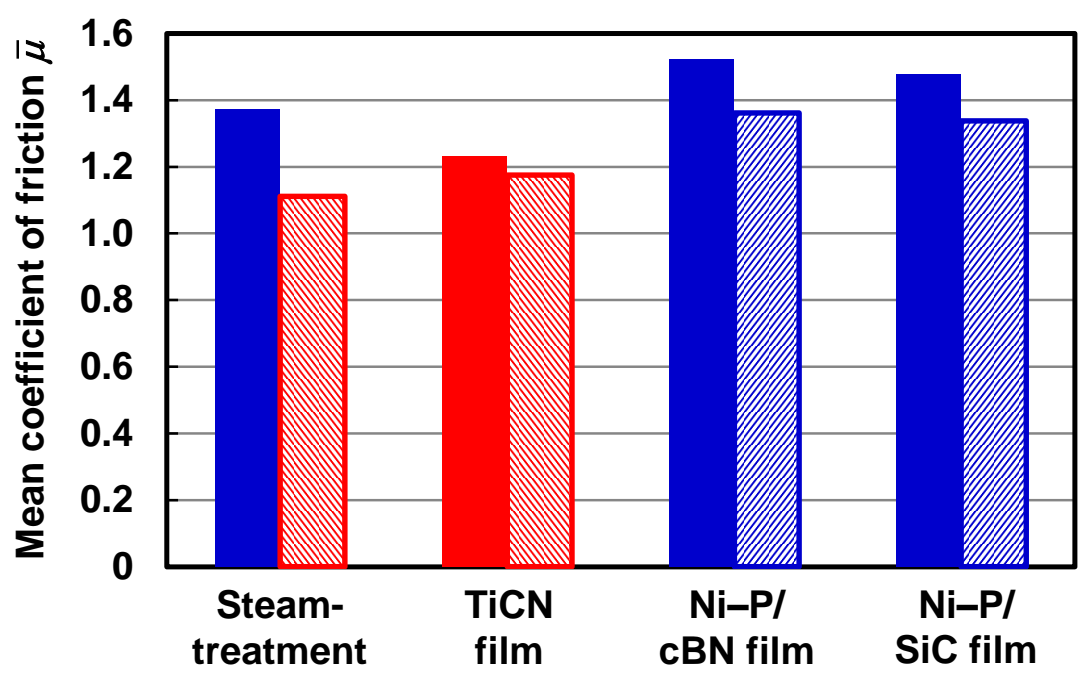

Figure 11 Mean coefficient of friction for each tapping tool at cutting velocity of 10 and $50 \mathrm{~m} / \mathrm{min}$

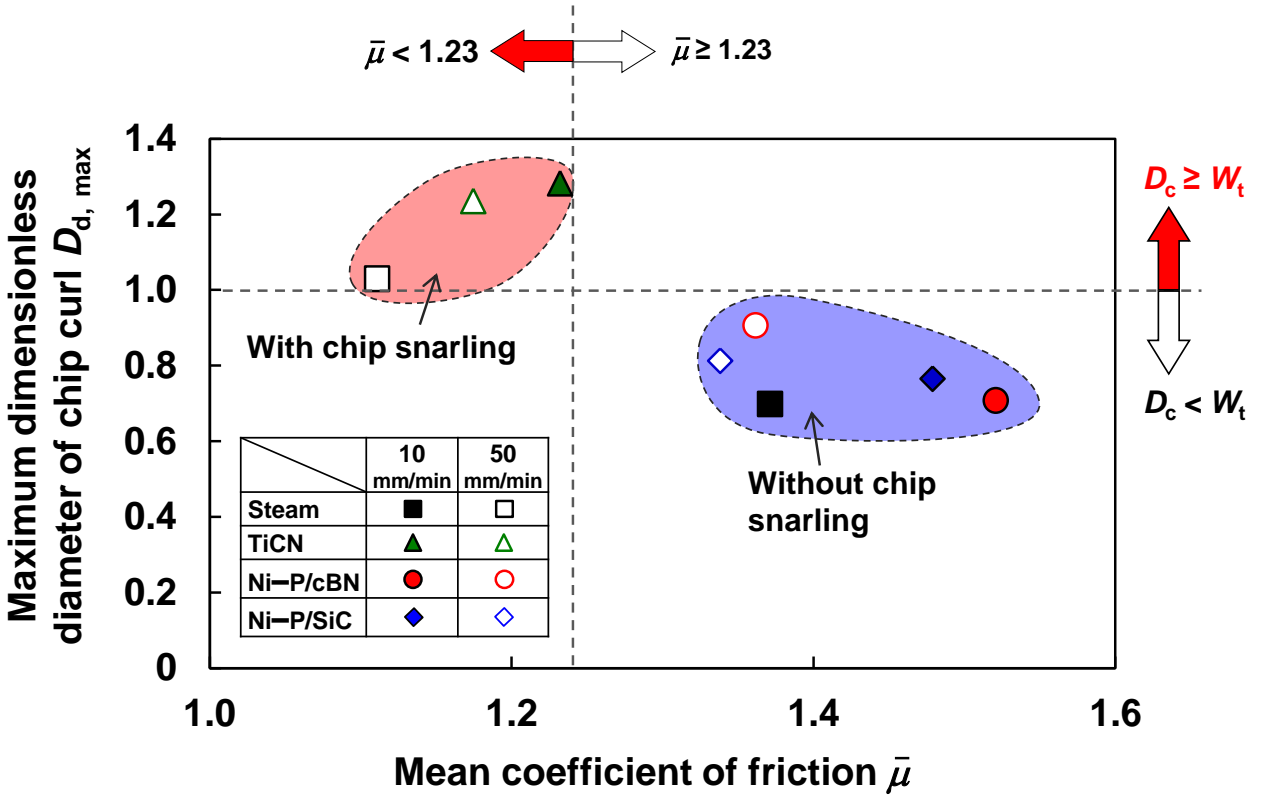

Figure 12 Relationship between coefficient of friction and maximum dimensionless diameter of chip curl 


\section{Conclusions}

In this study, the coefficient of friction between the rake face of the cutting edge of the tapping tool and the chip was estimated by measuring the thrust force and cutting torque during tapping. The relationship between the coefficient of friction and the chip curl diameter was investigated and the mechanism of prevention of chip snarling by using the cut tap coated with Ni-P/abrasive particles composite film was discussed. Conclusions obtained in this study are as follows:

1) The maximum dimensionless chip curl diameter for the tapping tool coated with the composite film was less than 1.0, whereas that for the conventional tapping tool with steam-treatment and that coated with TiCN film was greater than 1.0. The estimated coefficient of friction for the tapping tool coated with the composite film was greater than that for the other two tapping tools at both $10 \mathrm{~m} / \mathrm{min}$ and $50 \mathrm{~m} / \mathrm{min}$. High friction (with a mean coefficient of friction greater than 1.23) was necessary to prevent chip snarling at $10 \mathrm{~m} / \mathrm{min}$ and $50 \mathrm{~m} / \mathrm{min}$.

2) Ploughing friction caused by the abrasive particles on the tapping tool increased the coefficient of friction at the rake face-chip interface, which resulted in decreasing the chip curl diameter and preventing chip snarling even at a high cutting velocity.

\section{Acknowledgment}

This research was supported in part by the center for Revitalization Promotion, Japan Science and Technology Agency.

\section{References}

[1] A.C. Araujo, J.L. Silveira, M.B.G. Jun, S.G. Kapoor, R.D. Vor, A model for thread milling cutting forces, Int. J. Mach. Tool Manu. 46 (2006) 2057-2065.

[2] T. Cao, J.W. Sutherland, Investigation of thread tapping load characteristics through mechanistic modeling and experimentation, Int. J. Mach. Tool Manu. 42 (2002) 1527-1538.

[3] M. Yamauchi, O. Horiuchi, Y. Murakami, H. Sugano, H. Shibutani, Development of a chip-breaking tool for tapping ( $1^{\text {st }}$ report): prototype of the tool and its effectiveness, J. Jpn. Soc. Precis. Eng. 70 (2004) 1565-1569 (in japanese).

[4] Y. Yamaoka, Y. Kakino, T. Sato, Y. Suzuki, High speed, high productive tapping by intelligent machine tools ( $2^{\text {nd }}$ report): prevention of tap tool breakage and improvement of productivity by adaptive control, J. Jpn Soc. Precis. Eng. 67 (2000) 1338-342 (in Japanese).

[5] M. Jin, S. Watanabe, S. Miyake, M. Murakawa, Trial fabrication and cutting performance of c-BN-coated taps, Surf. Coatings Tech. 133-134 (2000) 443-47.

[6] E. Reiter, B. Brunner, M. Ante, J. Rechberger, Investigation of several PVD coatings for blind hole tapping in austenitic stainless steel, Surf. Coatings Tech. 200 (2006) 5532-541.

[7] V. Derflinger, H. Brändle, H. Zimmermann, New hard/lubricant coating for dry machining, Surf. Coatings Tech. 113 (1999) 286-92. 
[8] J. Yan, Y. Murakami, J.P. Davim, Tool design, tool wear and tool life, Machining dynamics, (2009) $117-149$.

[9] J.D. Kim, O.B. Kweun, A chip-breaking system for mild steel in turning, Int. J. Mach. Tool Manu. 37 (1997) 607-617.

[10] M.S.H. Bhuiyan, I.A. Choudhury, Y. Nukman, An innovative approach to monitor the chip formation effect on tool state using acoustic emission in turning, Int. J. Mach. Tool Manu. 58 (2012) 19-28.

[11] F. Ke, J. Ni, D.A. Stephenson, Continuous chip formation in drilling, Int. J. Mach. Tool Manu. 45 (2005) 1652-1658.

[12] A. Zabel, M. Heilmann, Deep hole drilling using tools with small diameters-process analysis and process design, CIRP Ann. 61 (2012) 111-114.

[13] Y. Saito, T. Yamaguchi, K. Shibata, Y. Kadota, T. Kubo, W, Watanabe, T. Sawabe, K. Hokkirigawa, Development of New Tapping Tool Covered with Nickel/Abrasive Particles Composite Film, Proceeding of The $16^{\text {th }}$ Nordic Symposium on Tribology (2014).

[14] Y. Saito, T. Yamaguchi, K. Shibata, Y. Kadota, T. Kubo, W. Watanabe, K. Hokkirigawa, Development of a New Tapping Tool Covered with Nickel/Abrasive Particles Composite Film for Preventing Chip Snarling and Tool Service Life Extension, Tribology Online, 11(2016).

[15] K. Nakayama, M. Uenoyama, K. Tamura, Chip curl in metal-cutting process, J. Jpn Soc. Precis. Eng. 27 (1961) 681-88 (in Japanese).

[16] J.N. Balaraju, T.S.N. Sankara Narayanan, S.K. Seshadri, Electroless Ni-P composite coatings, J Appl. Electrochem. 33 (2003) 807-816.

[17] G.S.Upadhyaya, Powder metallurgy technology, Cambridge Intl Science Pub. (1998).

[18] A. Hirota, Y. Mori, Prediction of chip formation and cutting forces in oblique cutting ( $2^{\text {nd }}$ report) -comparison of predicted and measured results-, J. Jpn Soc. Precis. 54(1988) 755-760 (in Japanese).

[19] T. Takeshima, N. Morita, S. Yamada, N. Takano, T. Oyama, The study of the cutting phenomenon by visualization of orthogonal cutting behaviour, J. Jpn Soc. Abrasive Tech. 49 (2005) 24-29. 